\title{
İnkomplet asetabular osteotomiler
}

\section{Incomplete iliac osteotomies}

\author{
Hakan Şenaran \\ Necmettin Erbakan Üniversitesi Meram Tıp Fakültesi, Konya
}

\begin{abstract}
Gelişimsel kalça displazisi tedavisinde, ileri yaşlarda, iliak osteotomi, sık kullanılan bir tedavi şeklidir. iliak osteotomiler, komplet (iliak kemiğin tam kat kesildiği) veya inkomplet (iliak kemik bütünlüğünün bozulmadığı) olarak ikiye ayrılır. İnkomplet osteotomiler arasında Pemberton ve Dega osteotomileri sıkça kullanılmaktadır. Pemberton osteotomisinde, iliak kemiğin hem mediyal hem lateral korteksi, supraasetabular bölgede triradiat kıkırdağa kadar kesilir ve dönme merkezi triradiat kıkırdaktır. Dega osteotomisinde ise lateral korteks mediyale doğru oblik kesilmekte ve dönme noktası gene triradiat kıkırdaktır.
\end{abstract}

Bu yazının amacı, günümüzde sıkça kullanılan Pemberton ve Dega osteotomilerinin (asetabuloplastilerinin) endikasyonları, teknikleri ve sonuçlarını tartışmaktır.

Anahtar sözcükler: inkomplet asetabular osteotomiler; Pemberton osteotomisi; Dega osteotomisi

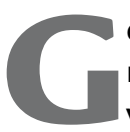

elişimsel kalça displazisi (GKD) hastalığında, rezidüel asetabular displazisinin tedavisinde ve eklem stabilitesi ve uyumunun arttırılması amacıyla birçok pelvik iliak osteotomi tanımlanmıştır. GKD tedavisinde uygulanacak işlem yaşa ve patolojinin tipine bağlı olarak değişir. Bu nedenle, osteotomiler, izole yapılabilecekleri gibi, kalçanın açık redüksiyonu ve femoral osteotomiler ile beraber de uygulanabilir. Iliak osteotomilerin uygulanabileceği minimum hasta yaşı konusunda tartışmalar olsa da, genel kanı yürüme yaşına gelmiş çocuklarda yapılabileceğidir. iliak osteotomiler, komplet ve inkomplet olarak iki gruba ayrılmaktadır. komplet iliak osteotomilere örnek olarak Salter, ${ }^{[1]}$ Steel ${ }^{[2]}$ ve Sutherland ${ }^{[3]}$ tarafından tanımlanan osteotomileri alabiliriz. Komplet osteotomiler, asetabuluma şekil vermeden asetabulumun yöneliminin değiştirilmesi yoluyla femur başının örtünmesini arttırmayı amaçlar ve bu nedenle yönlendirici (redirectional) osteotomiler olarak da bilinir. İnkomplet osteotomiler arasında ise, en sık kullanılan Pemberton osteotomisinin ${ }^{[4]}$ yanında, Albee ${ }^{[5]}$ ve Dega ${ }^{[6]}$ osteotomileri
Iliac osteotomy is a commonly used surgical treatment method in developmental hip dysplasia. Iliac osteotomies are classified as complete or incomplete. Pemberton and Dega osteotomies are among the most commonly applied incomplete iliac osteotomies. Both medial and lateral cortex of the iliac bone at the supraacetabular region were cut down back to the triaradiate cartilage at Pemberton osteotomy and rotation center is triradiate cartilage. Only lateral cortex of iliac bone is cut down to static notch and osteotome is directed medially to the triradiate cartilage at Dega osteotomy and rotation center is again triradiate cartilage.

In this review, indications, surgical technique and clinical results of Pemberton and Dega iliac osteotomies were discussed.

Key words: incomplete iliac osteotomies; Pemberton osteotomy; Dega osteotomy

tanımlanmıştır. İnkomplet osteotomiler, asetabuluma yeniden şekil verilmesi ile femur başının örtünmesinin arttırılmasını kolaylaştırdıkları için, yeniden şekillendirici (reshaping) osteotomiler olarak da tanımlanabilir.

Bu yazının amacı, günümüzde sıkça kullanılan Pemberton ve Dega osteotomilerinin (asetabuloplastilerinin) endikasyonları, teknikleri ve sonuçlarını tartışmaktır.

\section{PEMBERTON OSTEOTOMISI}

İnkomplet osteotomiler için kullanılan asetabuloplasti terimi, asetabulum üstünden yapılan ve asetabulumun aşağıya doğru devrilerek asetabulumun açısının azaltıldığı operasyonları tanımlar. Pemberton, osteotomisini perikapsüler iliak osteotomi olarak isimlendirmiştir. Bu osteotomide, iliak kemik mediyal ve lateralden, asetabulumun üst tarafından triradiat kıkırdağa kadar tam kat kesilir. Triradiat kıkırdak dönme merkezi olarak kullanılarak, asetabular çatı anterior ve laterale doğru devrilir. Pemberton, bu osteotomiyi uyguladığı

- Illetişim adresi: Prof. Dr. Hakan Şenaran, Necmettin Erbakan Üniversitesi Meram Tıp Fakültesi, Konya

Tel: 0532 - 4650613 e-posta: senaran@yahoo.com

- Geliș tarihi: 23 Ocak 2015 Kabul tarihi: 23 Ocak 2015 

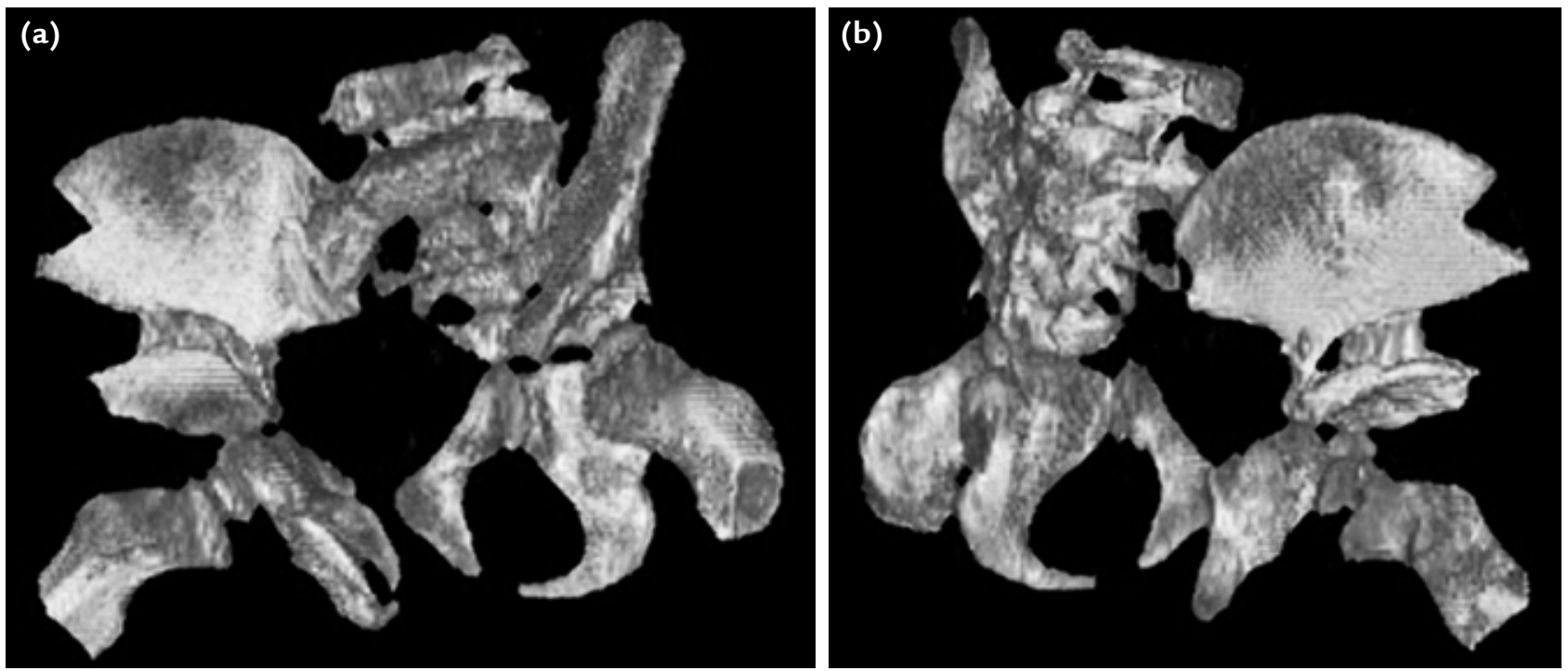

Şekil 1. a, b. Pemberton osteotomisi yapılmış bir hastanın kalçasının mediyalden (a) ve lateralden görünüşü (b).

91 hastanın 115 kalçasının an az iki yıllık sonuçlarını değerlendirmiş̧7] ve bu operasyonun bir yaş ile, triradiat kıkırdağın kapandığı yaş grubu arasındaki kalça displazisi hastalarında asetabular displazinin tedavisi amacıyla kullanılabileceğini ileri sürmüştür.

$\mathrm{Bu}$ osteotominin komplet osteotomilere en büyük avantajı, çoğunlukla, internal tespit ve daha sonra yapılacak implant çıkarımı işlemi gerektirmemesidir. Pemberton osteotomisi, teknik olarak zor bir osteotomi olmakla beraber, triradiat kıkırdak menteşe olarak kullanıldığı ve istenen düzeltme merkezi olan asetabuluma çok yakın olduğu için, yüksek açılarda düzeltme sağlayabilmektedir (Şekil 1); ayrıca, asetabulumun şeklini ve kapasitesini değiştirdiği için, femur başı ile asetabulum arasındaki uyumu etkileyebilmekte ve uzun dönemde bu uyumun sağlanması için asetabulumun yeniden şekillenmesi gerekmektedir.

\section{Teknik[8]}

- Hasta supin pozisyonda radyolusen masaya yatırılır ve opere edilecek kalçanın altına yükselti konur.

- iliofemoral veya ilioinguinal (bikini) kesisi yapılır.

- Kesinin üst tarafi, iliak kreste paralel şekilde spina iliaka anterior superiordan iliak krestin ortasına kadar uzatılır.

- Spina iliaka anterior superior distalinden sartorius ve tensor kaslarının arasından girilerek, rektus femoris kasının başı bulunur.

- Rektus başı kaldırılarak gerekli olduğu hallerde kapsül açılır, eklemin içi temizlenir ve açık redüksiyon ve kapsüloplasti yapılır.
- iliak apofiz üzerindeki abdominal kaslar sıyrıldıktan sonra, apofiz, ortasından iki yarıya kesilerek mediyale ve laterale doğru devrilir.

- Lateralde, gluteus ve tensor fasya lata kasları iliak kanadın anterior $1 / 3$ 'ünden subperiosteal olarak, distalde eklem kapsülüne, posteriorda siyatik çentiğe kadar sıyrilır.

- Mediyalde, keskin periosteal elevatör ile abdominal kaslar apofiz ile beraber kaldırıır ve iliak kanadın anterior 1/3'ünden subperiosteal olarak, iliak kas siyatik çentiğe kadar sıyrilır.

- iliak kanadın mediyal ve lateralinden, siyatik çentiğin görülmesi için iki adet künt $S$ ekartör yerleştirilir.

- Spina iliaka anterior inferiorun hemen üzerinden başlanarak, lateralde asetabulumun hemen $1 \mathrm{~cm}$ üzerinden çizıl osteotom ile, asetabuluma paralel şekilde kortikotomi yapılır. Daha sonra, dar eğri osteotom ile siyatik çentiğin görünen bölgesine kadar, asetabuluma paralel olacak şekilde, kortikotomiye devam edilir.

- Skopi ile bakılarak, lateralden osteotominin doğrultusu belirlenir. Eklem içine gitmediğinden emin olunmalıdır.

- Bu aşamada osteotominin ucu lateralde görünmeyebilir. Siyatik çentiğe girmeyecek ve asetabuluma paralel olacak şekilde, triradiat kıkırdağa kadar skopi eşliğinde osteotomiye devam edilir.

- Aynı şekilde, mediyalde spina iliak anterior inferior üzerinden başlanarak, asetabulumun $1 \mathrm{~cm}$ üzerinden, asetabuluma paralel olacak şekilde önce çizıl osteotom, sonra dar eğri osteotom ile, skopi eşliğinde asetabuluma ve siyatik çentiğe 

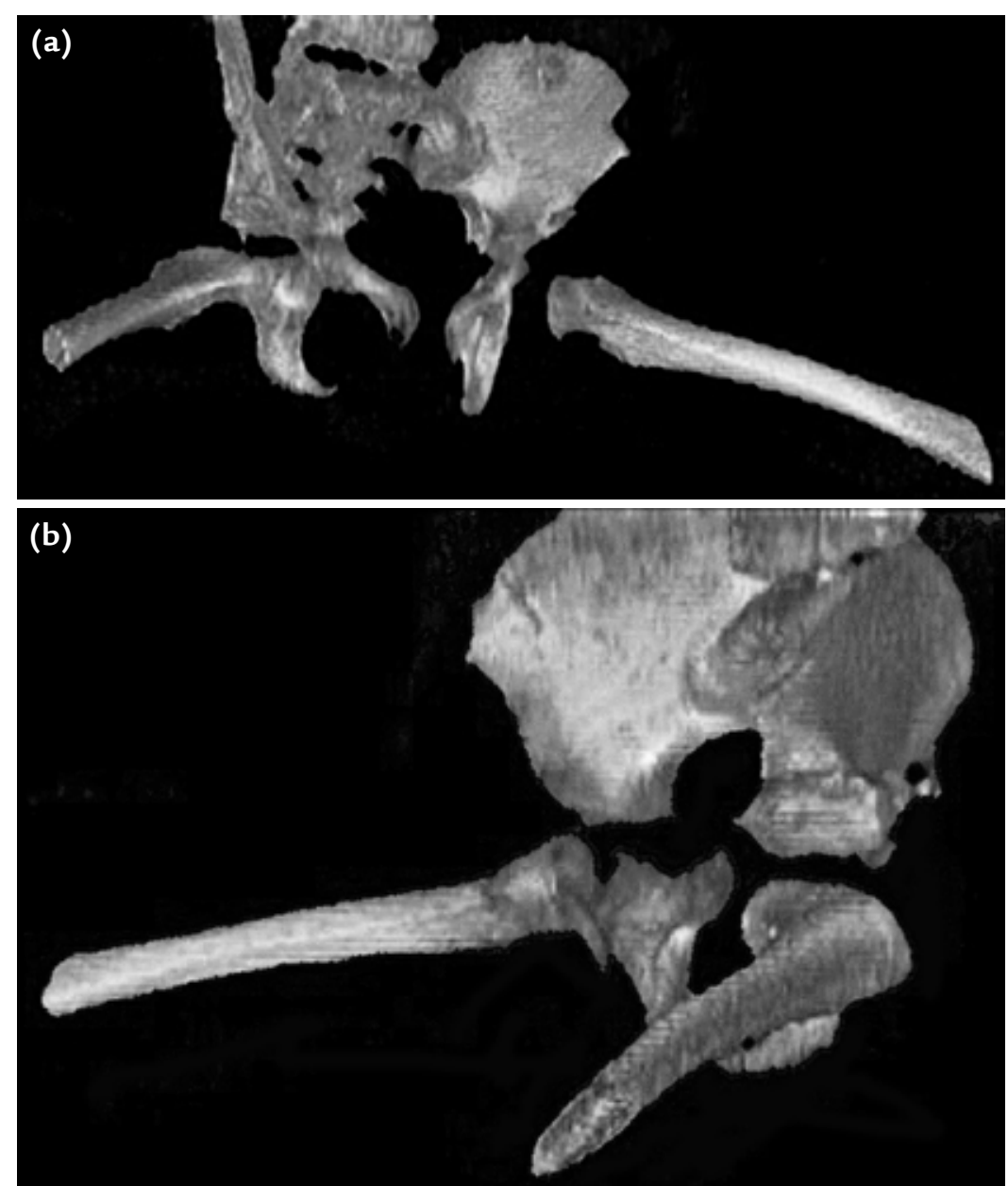

Şekil 2. a, b. Dega osteotomisi yapılmış bir hastanın kalçasının mediyalden (a) ve lateralden görünüşü (b).

girmediğimizden emin olarak, triradiat kıkırdağa kadar kortikotomi yapılır.

- iki tarafa yapılan osteotomilerin birleştirilmesi amacıyla, asetabulumun superiorundan geniş eğri osteotom kullanılır.

- Osteotomun triradiat kıkırdağa kadar uzandığından emin olduktan sonra, asetabular çatı, osteotom yardımı ile inferiora devrilir. Burada asetabular indeksin mümkün olduğunca azaltılması hedeflenmelidir.

- Lamina ayırıcı ile iliak osteotomi bölgesi ayrılır ve iliak kanattan alınan üçgen şeklinde kemik grefti araya sıkıştırılarak yerleştirilir.

- Stabilitenin yeterli olmadığının düşünüldüğü durumlarda, tek K-teli ile tespit gerekebilir.

- Yeterli redüksiyonun ve stabilitenin sağlandığı düşünülüyorsa, katlar kapatıldıktan sonra pelvipedal alçı uygulanır.

\section{DEGA OSTEOTOMISi}

Dega, kendi adıyla anılan transiliak osteotomiyi 1969 yılında tanımlamıştır. iliak kemiğin iç duvarının anterior ve orta kesimi, lateralden yapilan osteotomi ile kesilerek, posteriorda sağlam bırakılan bölge üzerinden asetabulum devrilir; gerekli durumlarda açık redüksiyon ve femoral osteotomi ile birlikte yapılabilir. Dega'nın kliniğinde uzun süredir yapılmakta olmasına rağmen, literatüre bu osteotomi ile ilgili yeterli katkı sağlanamamıştır. Grudziak, ${ }^{[6]} 2001$ yılında osteotomi hakkında ayrıntılı bir açıklama yayımlamıştır.

Dönme merkezinin değişebilmesi nedeniyle, Dega osteotomisi, triradiat kıkırdağın açık veya kapalı olduğu hastalarda yapılabilmektedir; ancak, açık olduğu durumlarda, GKD tedavisinde daha çok tercih edilmektedir. Özellikle serebral palsi hastalarında, triradiat kıkırdak kapandıktan sonra da Dega osteotomisi tercih edilebilmekte, asetabulumun posteriorunun örtünmesinde etkili olduğu rapor edilmektedir (Şekil 2). ${ }^{[6]}$ 


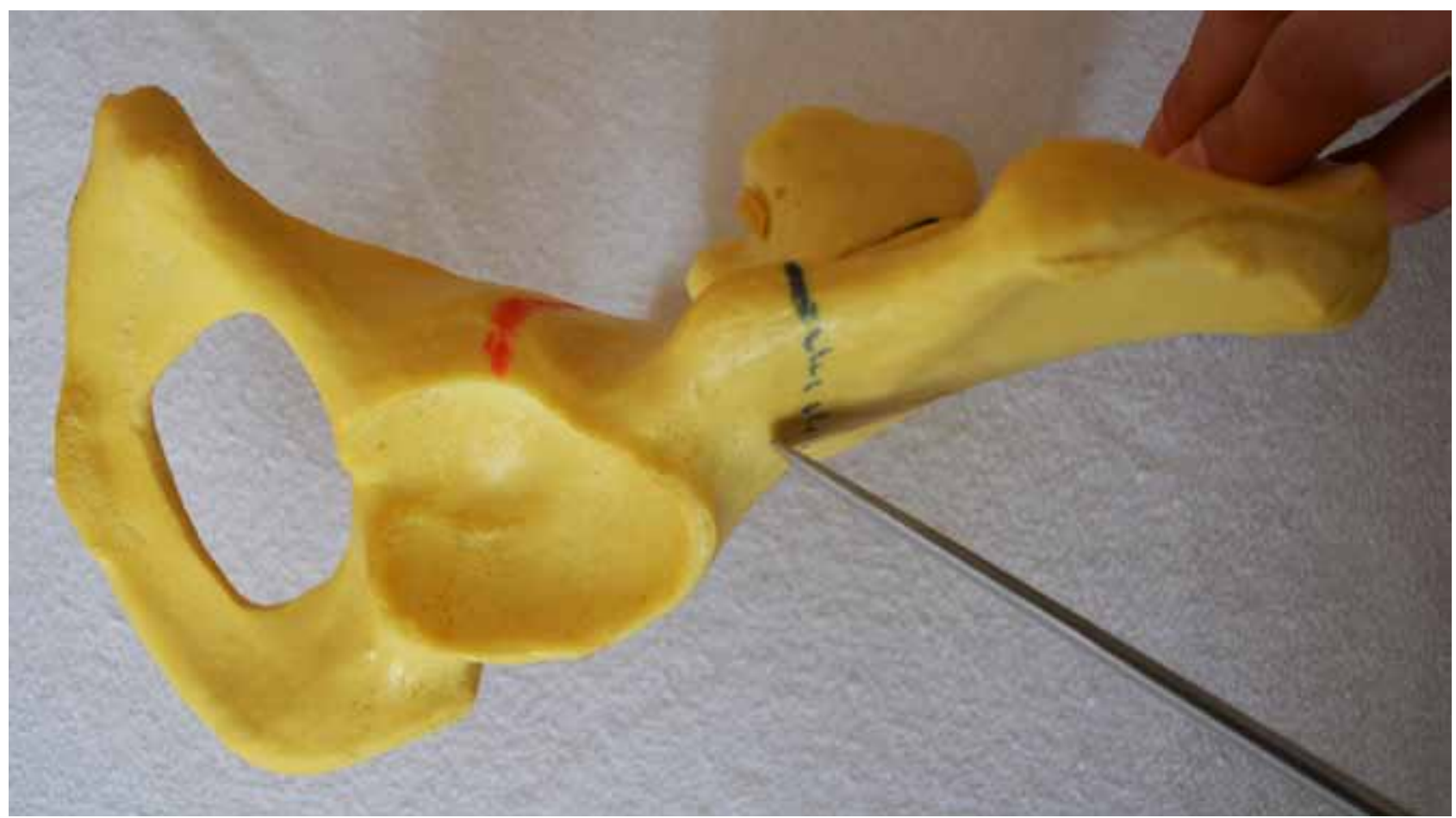

Şekil 3. Dega osteotomisinde düz osteotom, asetabulumun $1 \mathrm{~cm}$ üzerinde lateral korteksten, mediyale doğru triradiat kıkırdağın iliopübik ve ilioiskial kollarının tam ortasına yönlendirilir.

\section{Teknik ${ }^{[8]}$}

- Hasta supin pozisyonda radyolusen masaya yatırılır ve opere edilecek kalçanın altına yükselti konur.

- iliofemoral veya ilioinguinal (bikini) kesisi yapılır.

- Kesinin üst tarafı iliak kreste paralel şekilde, spina iliaka anterior superiordan iliak krestin ortasına kadar uzatılır.

- Spina iliaka anterior superior distalinden sartorius ve tensor kaslarının arasından girilerek, rektus femoris kasının başı bulunur.

- Rektus başı kaldırılarak gerekli olduğu hallerde kapsül açılır, eklemin içi temizlenir ve açık redüksiyon ve kapsüloplasti yapılır.

- iliak kemik lateralinden abduktor kaslar, subperiosteal olarak inferiorda eklem kapsülü, posteriorda siyatik çentik görülecek şekilde tamamen kaldırılır. Siyatik çentiğe Hohmann ekartör yerleştirilir. iliak kemiğin iç duvarı açılmaz.

- Kapsül üzerinde, rektus femorisin reflekte başı diseke edilerek kaldırılır.

- iliak kemik lateralinde, spina iliak anterior inferiorun önünden, asetabular kapsülün üzerinden, posteriorda siyatik çentiğe doğru kortikal osteotomi uygulanır. Osteotomi, posteriorda siyatik çentiğin $1-1,5 \mathrm{~cm}$ anteriorunda sonlandırılır.
Kortikotominin yerinin skopi eşliğinde tespit edilmesi gerekmektedir. Çok sığ asetabulum varlığında, yüksek noktadan kortikotomi yapmak, osteotominin eklem içine girmesini engelleyebilir.

- Asetabuluma yakın yapılan osteotomilerde, asetabular indekste açısal düzelme imkanı daha fazla olur.

- Düz osteotom, skopi kontrolünde, lateralde yapılan kortikotomiden, mediyale doğru triradiat kıkırdağın iliopübik ve ilioiskial kollarının tam ortasına yönlendirilir (Şekil 3).

- Daha çok anterior örtünme gerekiyorsa, mediyal iliak duvarın anterior ve orta bölümü kesilebilir. Sadece, posteriorda siyatik çentik sağlam bırakılarak, oradan döndürme sağlanır.

- Daha çok lateral ve posterior asetabular yetmezlik varsa ve asetabulumun posteriorunun örtünmesi isteniyorsa, mediyal duvar sağlam bırakılarak dönme noktası posteromediyal iç korteks olacak şekilde ayarlanabilir. Genellikle iç iliak duvarın posteriorda 1/3-1/4'lük kesimi sağlam bırakılır.

- Osteotomi bölgesinde, osteotom veya lamina ayırcı yardımıyla distraksiyon yapılır. Osteotomi bölgesi açıldıktan sonra iliak kanattan veya femoral kısaltma yapılmışsa femurdan alınan kemik grefti yerleştirilir. 
- Greftler yerleştirildikten sonra, yeterli stabilite genellikle sağlanır ve tespit ihtiyacı olmaz.

- Yeterli redüksiyonun ve stabilitenin sağlandığı düşünülüyorsa, katlar kapatıldıktan sonra pelvipedal alçı uygulanır.

\section{TARTIŞMA}

Hem Pemberton hem de Dega osteotomileri, inkomplet osteotomilerdir ve asetabulumun şeklini değiştirerek femur başının örtünmesini arttırdıkları kabul edilir. Yürüme yaşından sonra, asetabular displazisi bulunan çocuklarda uygulama endikasyonu vardır. Pemberton osteotomisi ile daha fazla asetabular açıda düzeltme sağlanabilmesi nedeniyle, yüksek asetabular düzeltme gereken çocuklarda Pemberton osteotomisi tercih edilebilir. Dega osteotomisi ise, osteotominin yerine göre dönme noktasının değişmesi nedeniyle lateral ve posterior örtünmeyi arttırmakta, bu nedenle GKD hastalarının yanında, serebral palsi hastalarında da sıklıkla tercih edilmektedir.

Pemberton osteotomisinde dönme noktası, triradiat kıkırdak; Dega osteotomisinde ise osteotominin yerine göre değişen miktarda mediyal iliak korteksin posterior, siyatik çentik, triradiat kıkırdağın horizontal kolu ve simfizis pubis olarak kabul edilebilir. Dega osteotomisinde, dönme merkezinin farklı yapılardan oluşması nedeniyle, triradiat kıkırdağın zarar görme riskinin Pemberton osteotomisi gibi sadece triradiat kıkırdaktan dönüş yapan osteotomilere göre daha az olduğuna inanılmaktadır. ${ }^{[6]}$ Asetabulumun yönlendirilmesi sonucu, Pemberton osteotomisinin anterior ve lateral örtünmeyi arttırdığı, Dega osteotomisinin ise dönme noktasına göre lateral ve posterior örtünmeyi daha fazla arttırdığı kabul edilmektedir.

Her iki osteotominin de asetabulumun şeklini değiştirdikleri kabul edilmektedir. Yapılan hayvan ve radyoloji çalışmalarında, her iki osteotominin de, asetabulum şeklini değiştirmesine rağmen, asetabulum hacmini azaltmadıkları gösterilmiştir. ${ }^{[9,10]}$ Bu nedenle, asetabuluma göre daha büyük görünen femur başı varlığında da tercih edilebilecekleri düşünülmektedir. Ayrıca, genellikle kemik grefti yerleştirildikten sonra stabil olmaları nedeniyle, internal tespit ihtiyacının olmaması da komplet osteotomilere göre avantaj olarak kabul edilebilir.

Uzun dönem sonuçları değerlendirildiğinde, her iki osteotominin de literatürde Salter osteotomisi kadar çok yer aldığı söylenemez. Salter osteotomisi ile Pemberton osteotomisinin radyolojik sonuçlarının karşılaştırıldığı bir çalışmada, Pemberton osteotomisinin asetabular derinlik indeksini arttırdığı tespit edilmiş ama asetabular indeks ve merkez kenar açısı değerlendirildiğinde, iki grup arasında fark bulunmamıştır. ${ }^{[11]}$ Ancak, Pemberton osteotomisinin avasküler nekroz ve asetabular retroversiyon riskini arttırdığı da belirtilmektedir. ${ }^{[12,13]}$ Dega osteotomisinin ise, radyolojik parametrelerde belirgin düzelme sağladığı ve daha az oranda asetabular retroversiyona neden olduğu belirtilmiştir. ${ }^{[14]}$ Literatürdeki çalışmalar, genellikle olgu serileri şeklindedir. Karşılaştırmalı çalışmalar olmadığı için, osteotomilerin birbirlerine karşı üstünlüklerinden veya dezavantajlarından bahsetmek mümkün değildir.

\section{KAYNAKLAR}

1. Wedge JH, Thomas SR, Salter RB. Outcome at forty-five years after open reduction and innominate osteotomy for late-presenting developmental dislocation of the hip. Surgical technique. J Bone Joint Surg Am 2008;90 Suppl 2 Pt 2:23853. CrossRef

2. Steel $\mathrm{HH}$. Triple osteotomy of the innominate bone. J Bone Joint Surg Am 1973;55(2):343-50.

3. Sutherland DH, Greenfield R. Double innominate osteotomy. J Bone Joint Surg Am 1977;59(8):1082-91.

4. Pemberton PA. Pericapsular osteotomy of the ilium for treatment of congenital subluxation and dislocation of the hip. J Bone Joint Surg Am 1965;47:65-86.

5. Albee $\mathrm{FH}$. The bone graft wedge. Its use in the treatment of relapsing, acquired, and congenital dislocation of the hip. New York Med J 1915;102:433-5.

6. Grudziak JS, Ward WT. Dega osteotomy for the treatment of congenital dysplasia of the hip. J Bone Joint Surg Am 2001;83-A(6):845-54.

7. Pemberton PA. Pericapsular osteotomy of the ilium for the treatment of congenitally dislocated hips. Clin Orthop Relat Res 1974;(98):41-54.

8. Canale ST, Beaty JH, editors. Campbell Operative Orthopaedics, 12th ed. 2013.

9. Cummings RJ. How the pemberton innominate osteotomy really works: an animal study. J Surg Orthop Adv 2004;13(3):166-9.

10. Ozgur AF, Aksoy MC, Kandemir U, Karcaaltncaba M, Aydingoz U, Yazici M, Surat A. Does Dega osteotomy increase acetabular volumein developmental dysplasia of the hip? J Pediatr Orthop B 2006;15(2):83-6.

11. Ertürk $C$, Altay MA, Işikan UE. A radiological comparison of Salter and Pemberton osteotomies to improve acetabular deformations in developmental dysplasia of the hip. J Pediatr Orthop B 2013;22(6):527-32. CrossRef

12. Akiyama $M$, Nakashima $Y$, Oishi $M$, Sato $T$, Hirata $M$, Hara $D$, Iwamoto $Y$. Risk factors for acetabular retroversion in developmental dysplasia of the hip: does the Pemberton osteotomy contribute? J Orthop Sci 2014;19(1):90-6. CrossRef

13. Wu KW, Wang TM, Huang SC, Kuo KN, Chen CW. Analysis of osteonecrosis following Pemberton acetabuloplasty in developmental dysplasia of the hip: long-term results. J Bone Joint Surg Am 2010;92(11):2083-94. CrossRef

14. Rampal V, Klein C, Arellano E, BoubakeurY, Seringe R, Glorion C, Wicart P. Outcomes of modified Dega acetabuloplasty in acetabular dysplasia related to developmental dislocation of the hip. Orthop Traumatol Surg Res 2014;100(2):203-7. CrossRef 